\title{
Online Detection of Selenium and its Retention in Reducing Gasification Atmosphere
}

\author{
Philip Edinger, ${ }^{*[a, b]}$ Mohamed Tarik, ${ }^{[a]}$ Adrian Hess, ${ }^{[a, b]}$ Andrea Testino, ${ }^{[a]}$ \\ Christian Ludwig *[a,b]
}

Supporting Information

${ }^{[a]}$ Paul Scherrer Institut (PSI), ENE, 5232 Villigen PSI (Switzerland)

${ }^{[b]}$ École Polytechnique Fédérale de Lausanne, (EPFL), ENAC-IIE, 1015 Lausanne (Switzerland)

* corresponding authors:

Philip Edinger, e-mail: philip.edinger@alumni.ethz.ch

Prof. Christian Ludwig, e-mail: christian.ludwig@epfl.ch 


\section{Estimation of Expected Se Emission Limitation}

Based on the final US EPA rule, an estimation on allowable $\mathrm{H}_{2} \mathrm{Se}$ concentrations in the flue gas of IGCC processes can be made ${ }^{1}$. Because the control of Se concentration is assumed to take place before the gas turbine (see Introduction) of the IGCC process, these conditions lay the basis for the following calculations. The given Se emission limitation is expressed by the parameter $\alpha_{\mathrm{EPA}}$ in Eq. (SI.1). Based on this value, the allowable gas concentration $\mathrm{y}_{\mathrm{Se}, \mathrm{EPA}}$ can be calculated as shown in Eq. (SI.3). In this equation $\beta$ represents a relation between the coal feed to the gasifier and the exiting volumetric raw gas flow ${ }^{2}, V_{m}$ the molar volume, $\eta_{e l}$ the electric efficiency of the power plant $\left(\eta_{\mathrm{el}}=0.4\right)$ and $\mathrm{LHV}_{\text {coal }}$ the lower heating value of coal $\left(\operatorname{LHV}_{\text {coal }}=\right.$ $24 \mathrm{MJ} / \mathrm{kg})$.

$\alpha_{\mathrm{EPA}}=0.3 \frac{\mathrm{lb}(\mathrm{Se})}{\mathrm{GWh}} \frac{0.4536 \mathrm{~kg}(\mathrm{Se})}{\mathrm{lb}(\mathrm{Se})} \frac{\mathrm{h}}{3600 \mathrm{~s}}$

$\beta=0.48 \frac{\mathrm{kg}(\mathrm{coal})}{\mathrm{Nm}^{3}}$

$\mathrm{y}_{\mathrm{Se}, \mathrm{EPA}}=\frac{\alpha_{\mathrm{EPA}} \beta V_{\mathrm{m}} \eta_{\mathrm{el}} L_{\mathrm{L}} \mathrm{V}_{\text {coal }}}{\mathrm{M}_{\mathrm{Se}}} \cong 50 \mathrm{ppbv}$ 


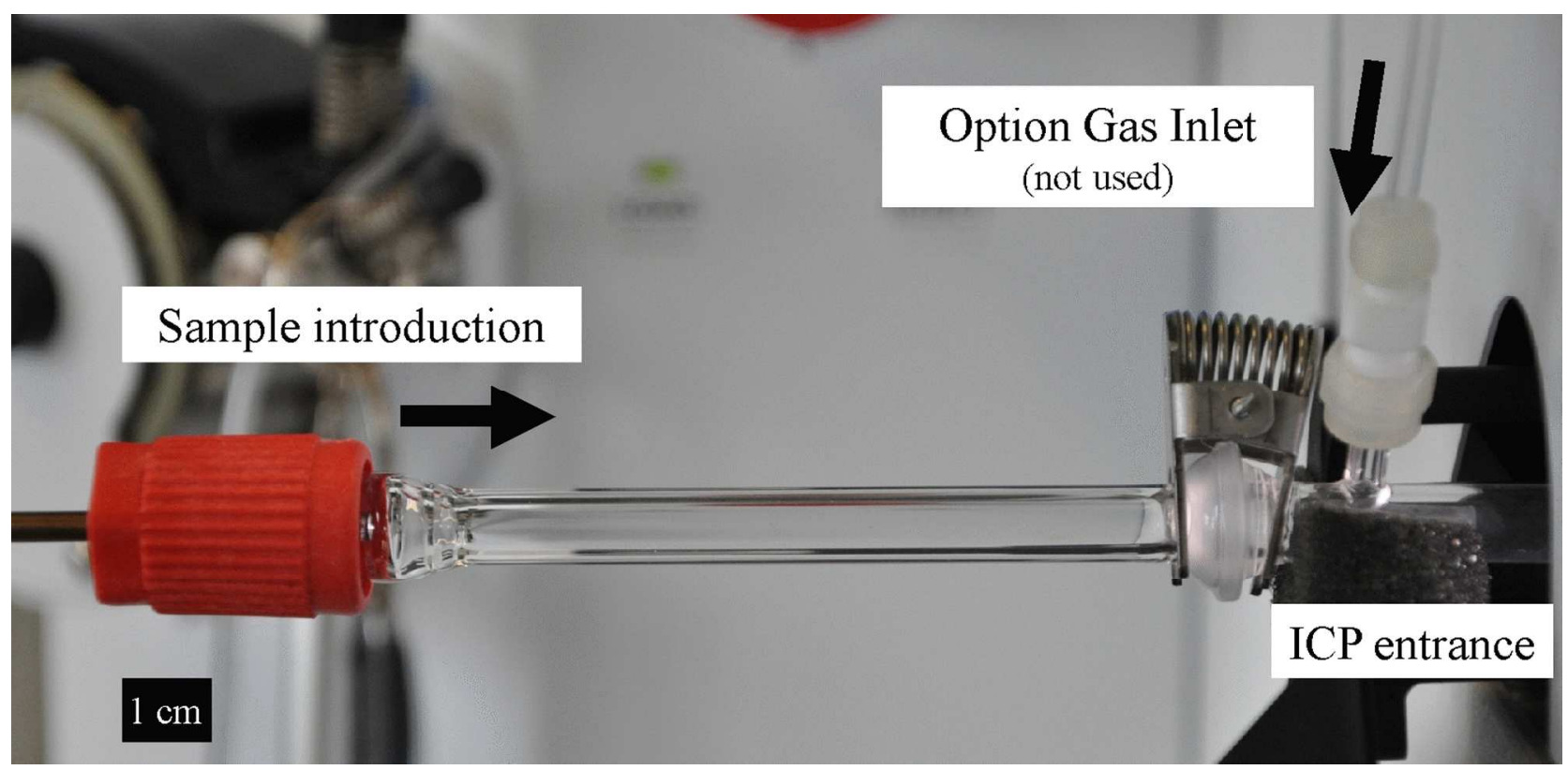

Figure SI.1 - Quartz adapter (similar to the connector tube of the used ICP instrument), directly connected to the plasma torch 


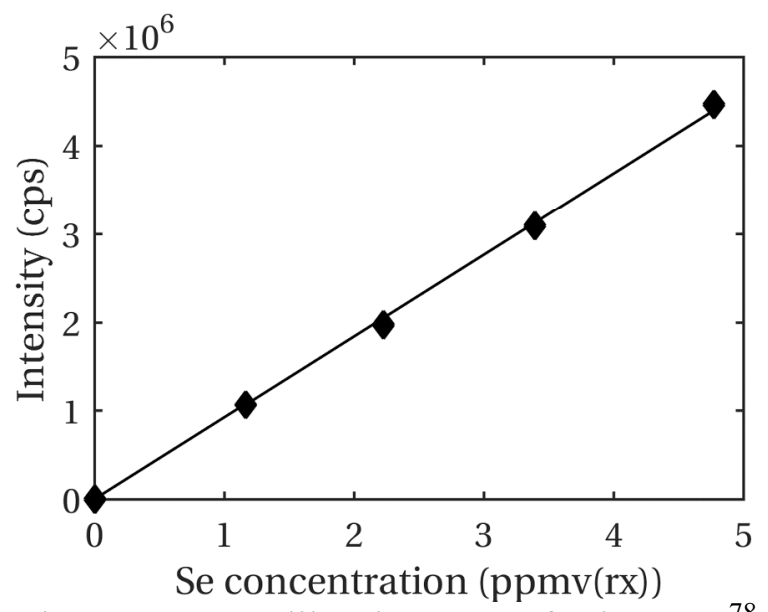

Figure SI.2 - Calibration curve for isotope ${ }^{78} \mathrm{Se}$, performed with experimental setup 1 
Verification of Detection Limits with Setup 2

Figure SI.3 (a) depicts the calibration curve for isotope ${ }^{78} \mathrm{Se}$, measured with experimental setup 2. Figure SI.3 (b) shows the measured intensities of the ${ }^{78} \mathrm{Se}$ isotope for the blank experiment and a feed of $0.6 \mathrm{ppbv}(\mathrm{rx}) \mathrm{H}_{2} \mathrm{Se}$ as well as the corresponding averages of these experiments marked by dashed lines. The dashed line, representing the intensity $\mathrm{I}_{\mathrm{LOD}}$ of the detection limit, is calculated according to Eq.(SI.4). In this equation, $\mathrm{I}_{\mathrm{b}}$ refers to the measured background intensity of ${ }^{78} \mathrm{Se}$. The intensity for an $\mathrm{H}_{2} \mathrm{Se}$ inlet concentration of $0.6 \mathrm{ppbv}(\mathrm{rx})$ lies clearly above the calculated LOD intensity of $0.54 \mathrm{ppbv}(\mathrm{rx})$.

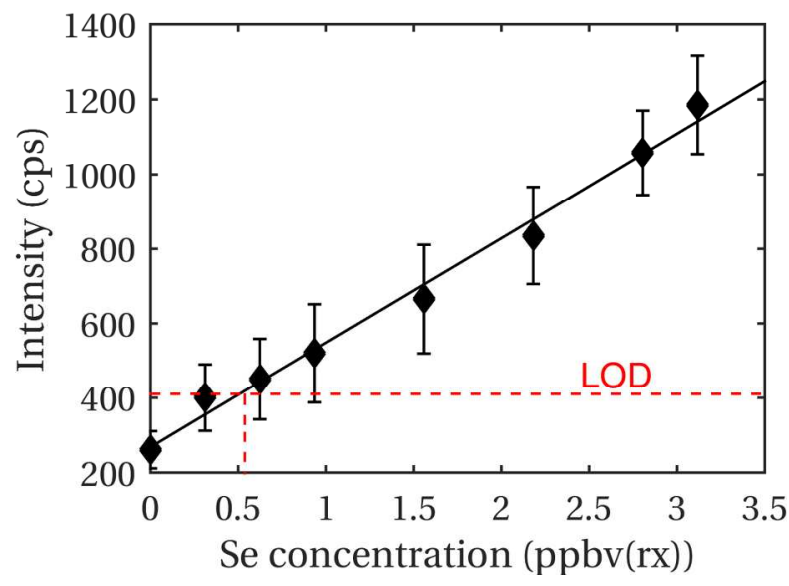

(a)

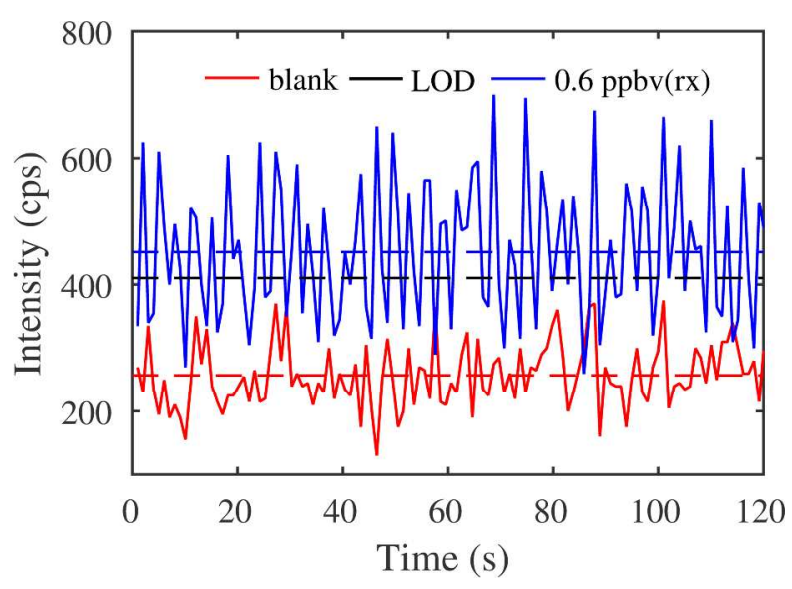

(b)

Figure SI.3 - (a) Calibration curve for isotope ${ }^{78} \mathrm{Se}$, performed with experimental setup 1; (b) measured intensities for blank measurement and a $\mathrm{H}_{2} \mathrm{Se}$ concentration of $0.6 \mathrm{ppbv}(\mathrm{rx})$.

$\mathrm{I}_{\mathrm{LOD}}=3 \mathrm{~s}_{\mathrm{b}}+\mathrm{I}_{\mathrm{b}}$ 
Spectral Analysis of Signals Measured with Setup 2

The recorded signals for the blank and $0.6 \mathrm{ppbv}(\mathrm{rx}) \mathrm{H}_{2} \mathrm{Se}$ concentration are presented in Figure SI.4 and Figure SI.6. Both experiments were performed with setup 2. In order to find possible dominant frequencies in the recorded time series, periodograms were calculated for each case ${ }^{3}$ and are shown in Figure SI.5 and Figure SI.7. No dominant frequency can be observed for $0 \operatorname{ppbv}(\mathrm{rx}) \mathrm{H}_{2} \mathrm{Se}$ concentration. This is coherent with the fact that the RDD was not rotating. However, at $0.6 \mathrm{ppbv}(\mathrm{rx}) \mathrm{H}_{2} \mathrm{Se}$ concentration, a feature at $18.8 \mathrm{~min}^{-1}$ is observed, a frequency that can be related to the rotating disk speed of the RDD.

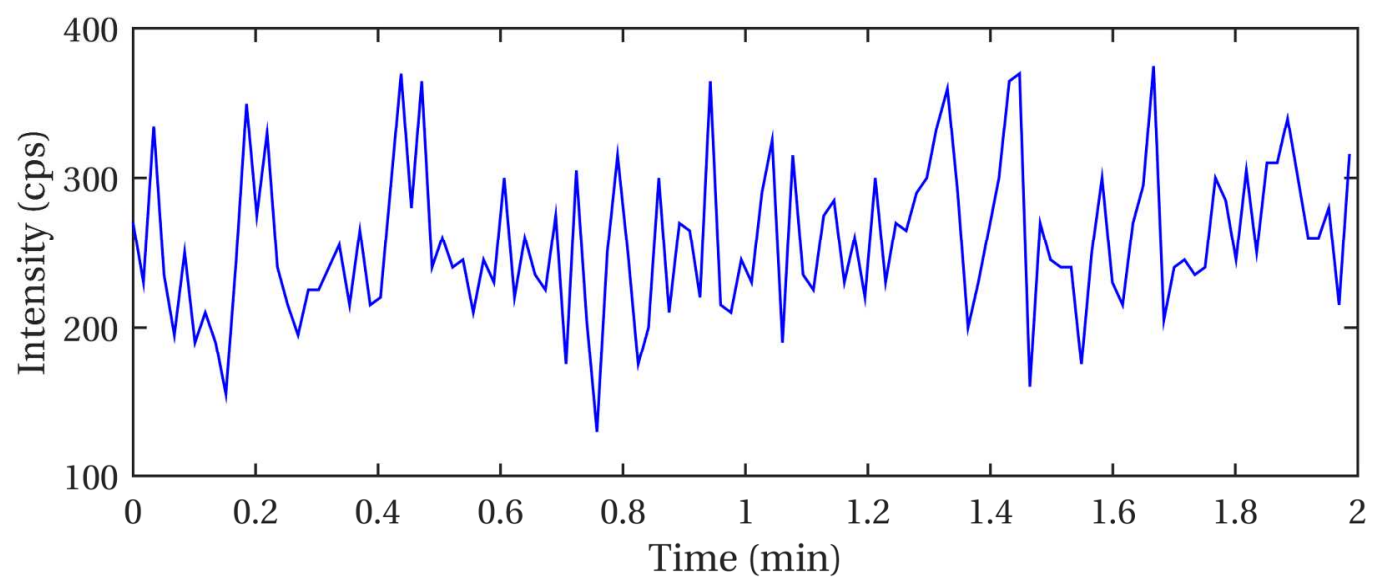

Figure SI.4 - Measured intensity versus time for $0 \mathrm{ppbv(rx)} \mathrm{H}_{2} \mathrm{Se}$ (obtained with setup 2)

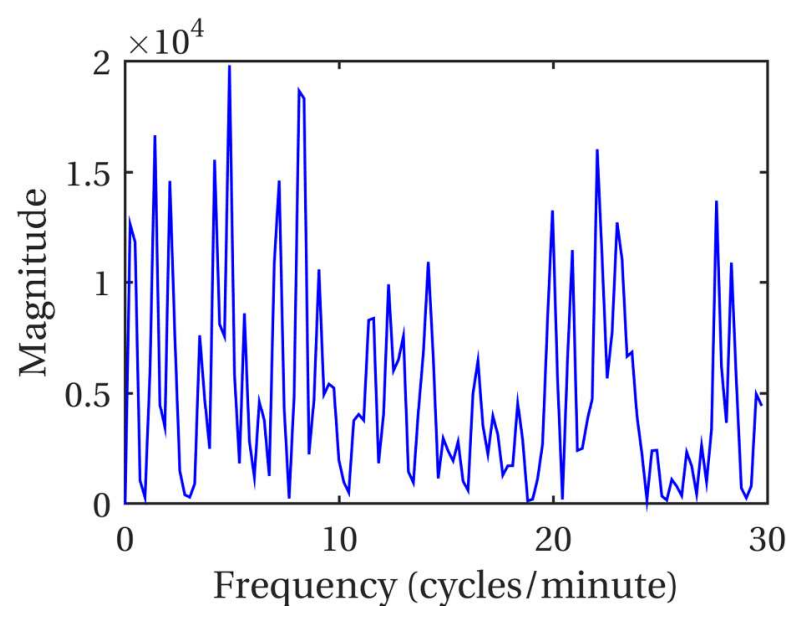

Figure SI.5 - Periodogram calculated from data presented in Figure SI.4 


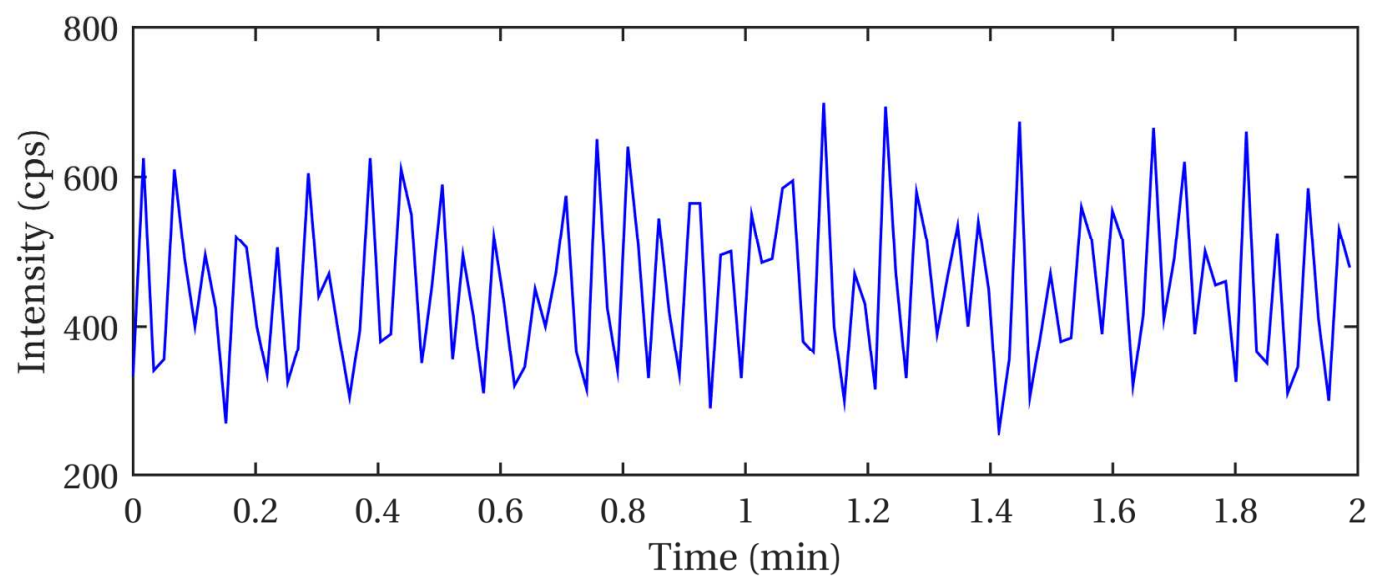

Figure SI.6 - Measured intensity versus time for $0.6 \mathrm{ppbv}(\mathrm{rx}) \mathrm{H}_{2} \mathrm{Se}$ (obtained with setup 2)

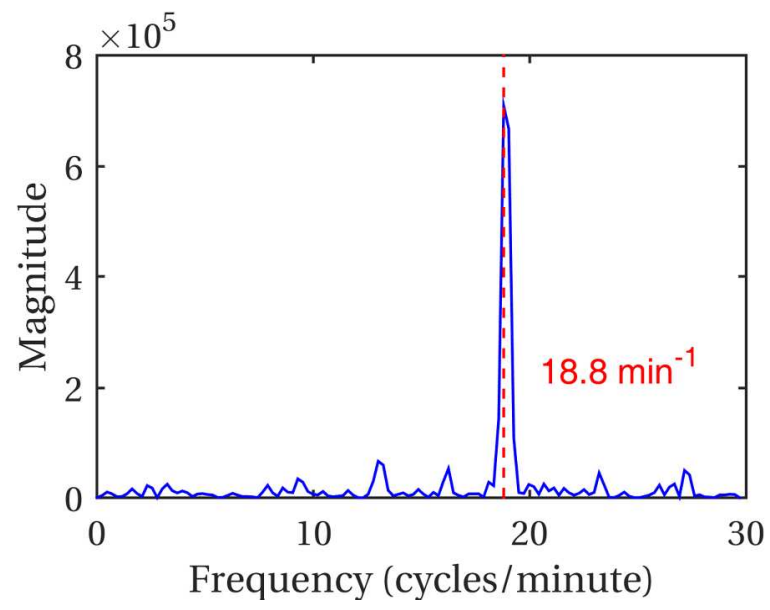

Figure SI.7 - Periodogram calculated from data presented in Figure SI.6 
Calculation of Physical Properties of Flow through Sorbent Bed

For the calculation of the physical properties of the fluid phase in the packed sorbent bed, several assumptions were made. The viscosity of the fluid is calculated according to Wilke ${ }^{4}$, assuming a $\mathrm{H}_{2}$-Ar gas mixture. Calculation of the gas density uses the ideal gas law with averaged molecular weights.

Measured values of the diffusivity of $\mathrm{H}_{2} \mathrm{Se}$ are not readily available. The diffusivity was therefore calculated from the known, chemically similar, species $\mathrm{H}_{2} \mathrm{~S}$, based on the relationship of diffusivities to molecular weight in Eq. (SI.5) ${ }^{5}$. In this equation, the $\mathrm{D}_{\mathrm{x}}$ refer to the diffusivities and $\mathrm{M}_{\mathrm{x}}$ to the molecular weights.

Based on this diffusivity, the diffusion coefficient $\mathrm{D}$ of $\mathrm{H}_{2} \mathrm{Se}$ in $\mathrm{Ar}$ can be calculated according to the Fuller equation ${ }^{6}$. The axial dispersion coefficient $\mathrm{D}_{\mathrm{ax}}$ is calculated according to Eq. (SI.6), where $\varepsilon_{\mathrm{B}}$ refers to the bed porosity ${ }^{7}$.

$D_{\mathrm{H}_{2} \mathrm{Se}}=\mathrm{D}_{\mathrm{H}_{2} \mathrm{~S}}\left(\frac{\mathrm{M}_{\mathrm{H}_{2} \mathrm{Se}}}{\mathrm{M}_{\mathrm{H}_{2} \mathrm{~S}}}\right)^{-0.5}$
$\mathrm{D}_{\mathrm{ax}}=\mathrm{D}\left(1-\sqrt{1-\varepsilon_{\mathrm{B}}}\right)+\frac{\mathrm{u}_{0} \mathrm{~d}_{\mathrm{p}}}{2}$ 


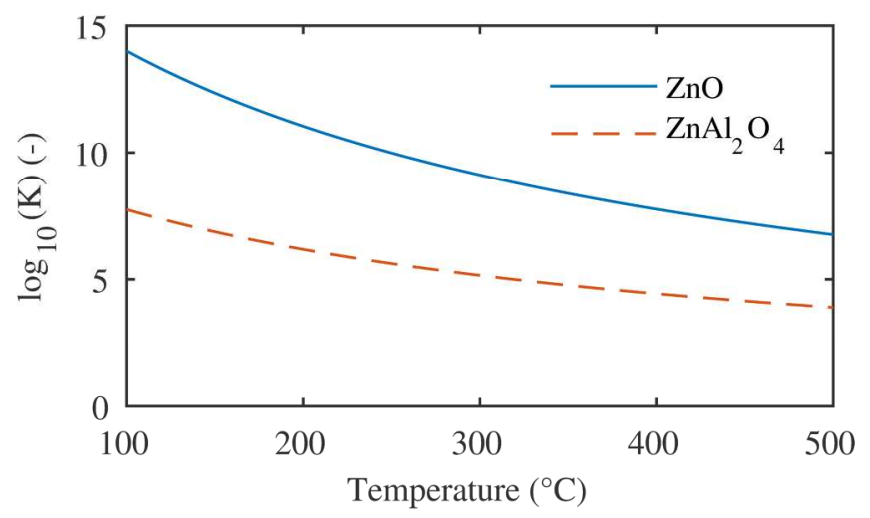

Figure SI.8 - Equilibrium constants for the system $\mathrm{ZnO}_{(\mathrm{s})}+\mathrm{H}_{2} \mathrm{Se}_{(\mathrm{g})} \leftrightarrow \mathrm{ZnSe}_{(\mathrm{s})}+\mathrm{H}_{2} \mathrm{O}_{(\mathrm{g})}$ (blue) and for the system $\mathrm{ZnAl}_{2} \mathrm{O}_{4(\mathrm{~s})}+\mathrm{H}_{2} \mathrm{Se}_{(\mathrm{g})} \leftrightarrow \mathrm{ZnSe}_{(\mathrm{s})}+\mathrm{Al}_{2} \mathrm{O}_{3(\mathrm{~s})}+\mathrm{H}_{2} \mathrm{O}_{(\mathrm{g})}$ (red - dashed) 


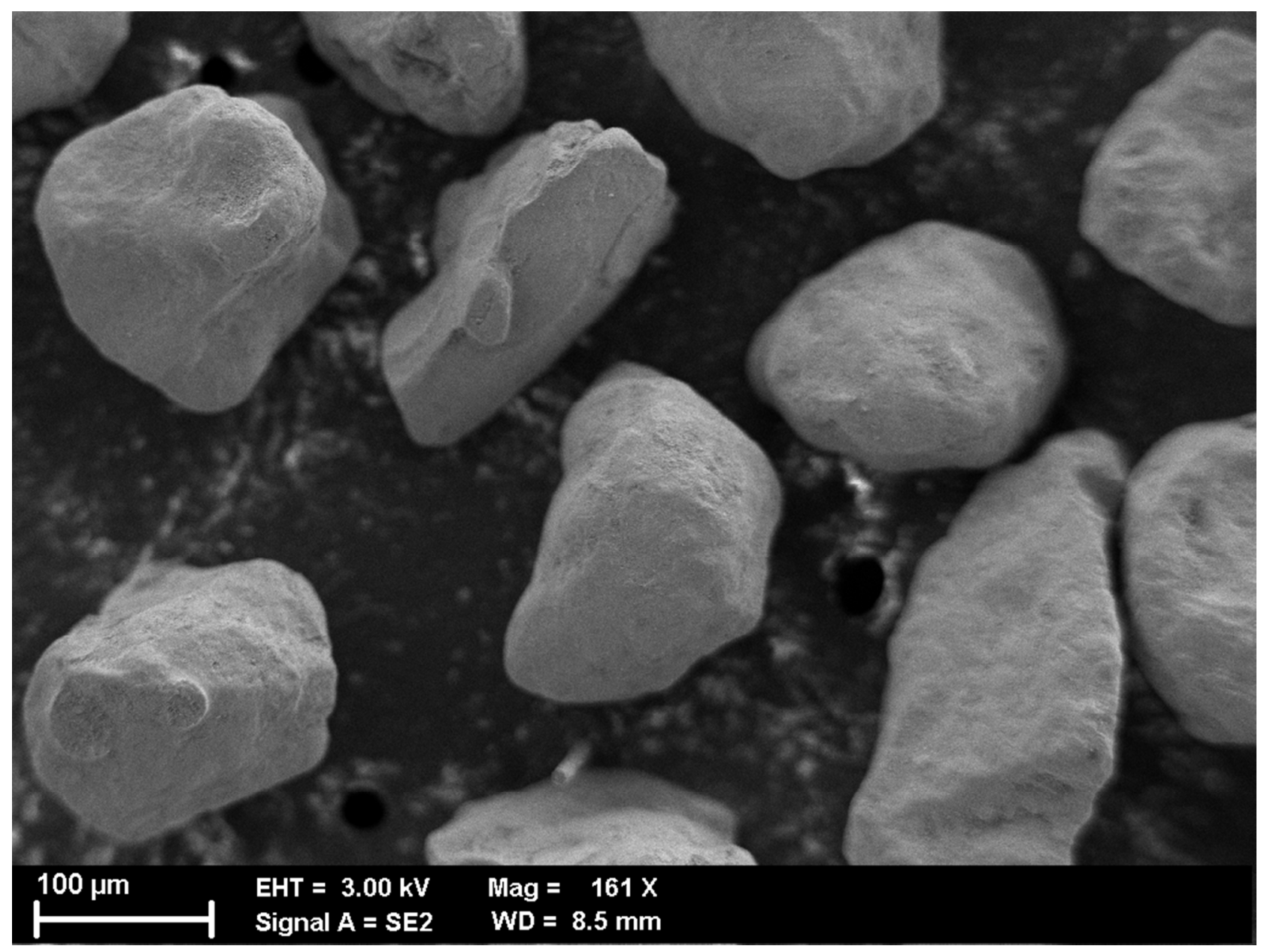

Figure SI.9 -SEM picture of $0.89 \mathrm{wt} \% \mathrm{Zn} / \mathrm{Al}_{2} \mathrm{O}_{3}$ sorbent before experiment 


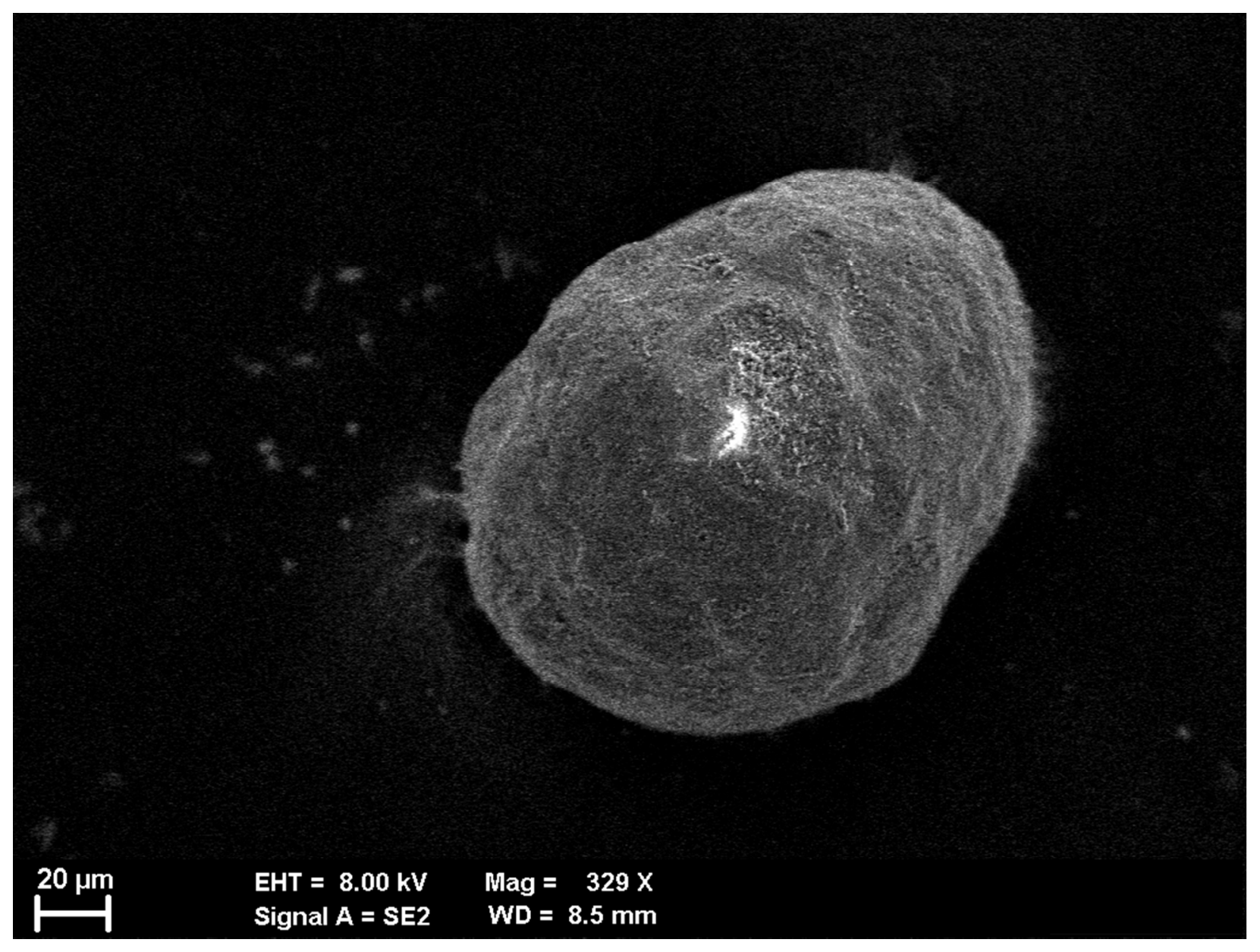

Figure SI.10 - SEM picture of $0.89 \mathrm{wt} \% \mathrm{Zn} / \mathrm{Al}_{2} \mathrm{O}_{3}$ sorbent after experiment 


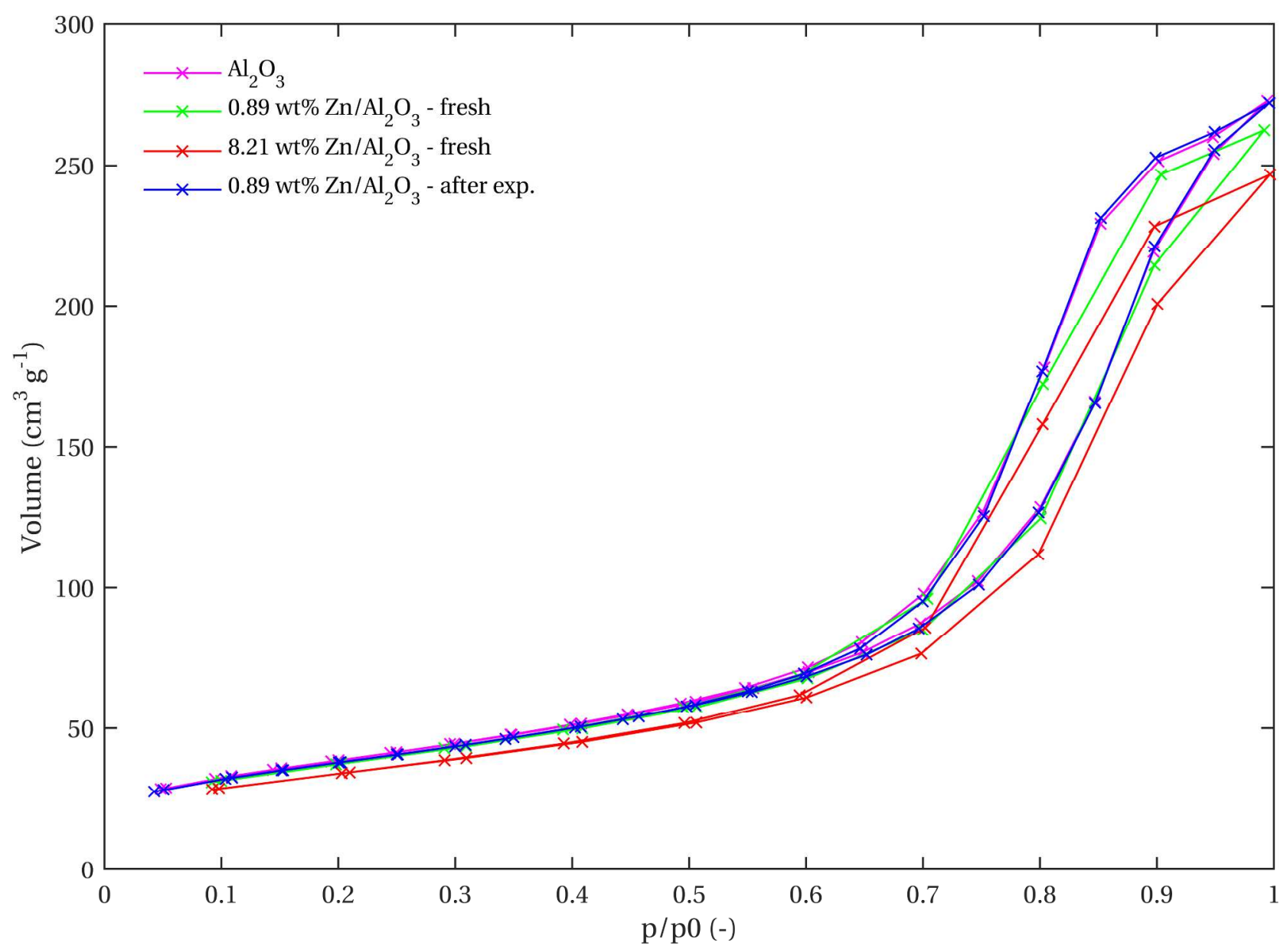

Figure SI.11 $-\mathrm{N}_{2}$ adsorption-desorption isotherms of $\mathrm{Al}_{2} \mathrm{O}_{3}$ support and $\mathrm{Zn} / \mathrm{Al}_{2} \mathrm{O}_{3}$ sorbent materials at $77 \mathrm{~K}$ 


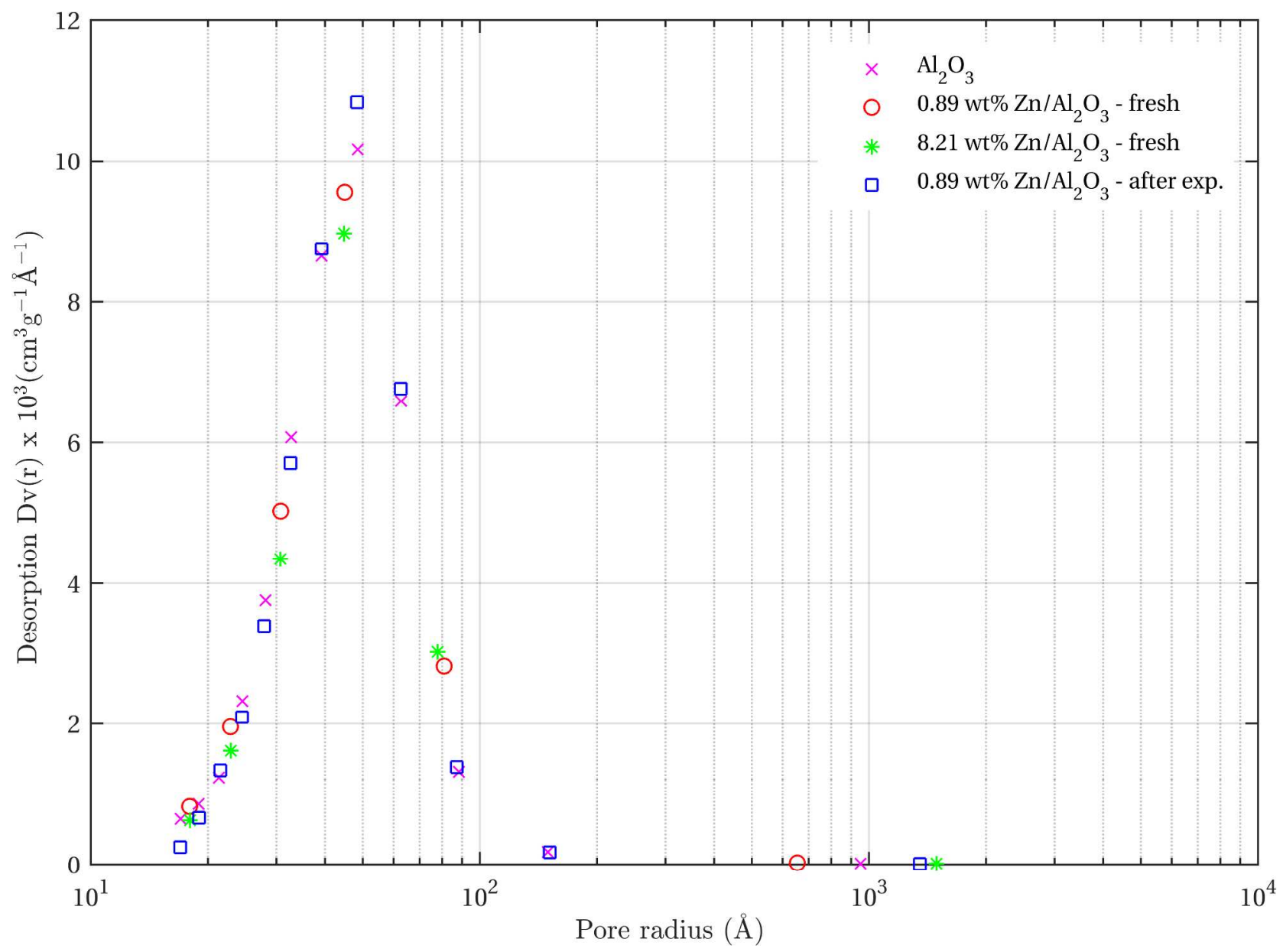

Figure SI.12 - Pore size distributions (as calculated by BJH method) of $\mathrm{Al}_{2} \mathrm{O}_{3}$ support and $\mathrm{Zn} / \mathrm{Al}_{2} \mathrm{O}_{3}$ sorbent materials 
Breakthrough curves for two repetition experiments

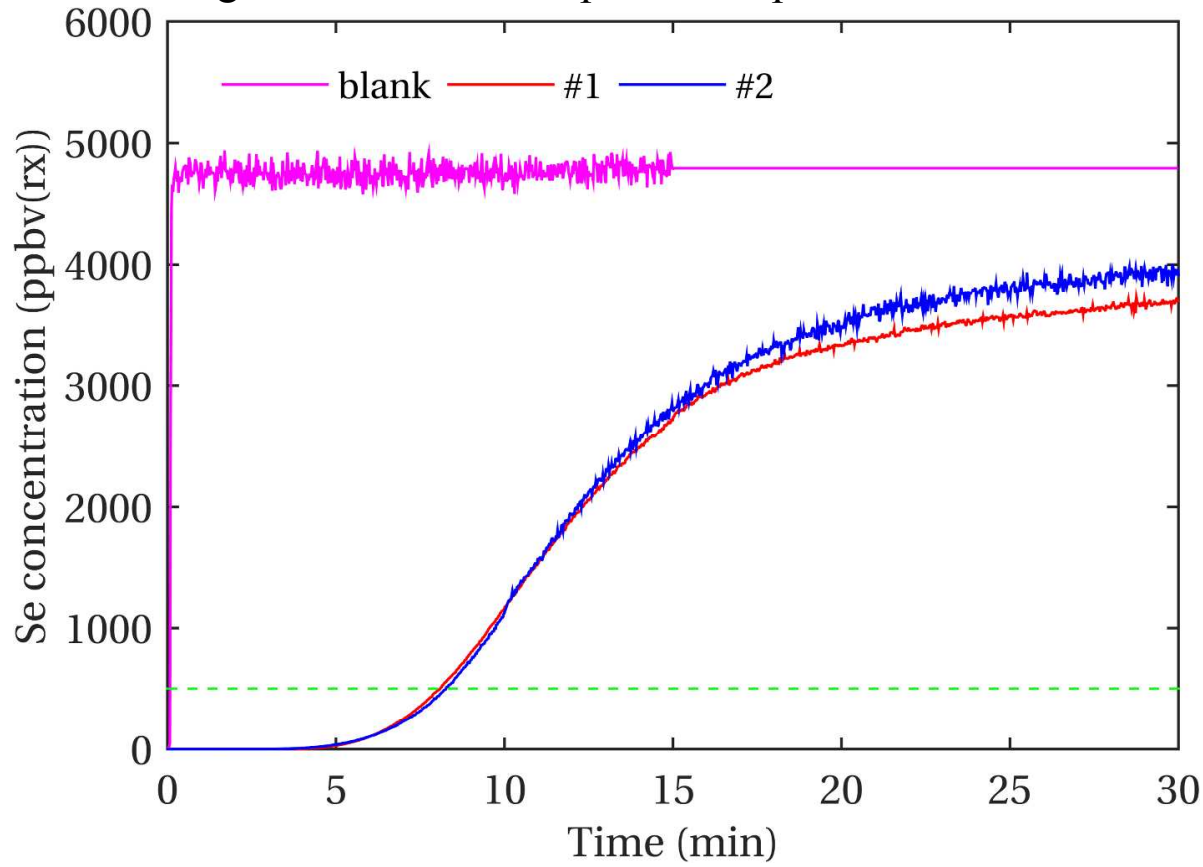

Figure SI.13 - Breakthrough curves for two repetition experiments $\left(250^{\circ} \mathrm{C} ; 0.89 \mathrm{wt} \% \mathrm{Zn} / \mathrm{Al}_{2} \mathrm{O}_{3}\right.$; reactor inlet: 40 vol\%(rx) $\mathrm{H}_{2}, 5$ vol\%(rx) $\mathrm{H}_{2} \mathrm{O}, 4770 \mathrm{ppbv}(\mathrm{rx}) \mathrm{H}_{2} \mathrm{Se}$, balance Ar. The dashed green line marks the breakthrough concentration $(\chi=500 \mathrm{ppbv}(\mathrm{rx}))$.

Table SI. 1 - Overview of results for two repetition experiments $\left(250^{\circ} \mathrm{C} ; 0.89 \mathrm{wt} \% \mathrm{Zn} / \mathrm{Al}_{2} \mathrm{O}_{3}\right.$; reactor inlet: 40 vol\%(rx) $\mathrm{H}_{2}, 5$ vol\%(rx) $\mathrm{H}_{2} \mathrm{O}, 4770 \mathrm{ppbv}(\mathrm{rx}) \mathrm{H}_{2} \mathrm{Se}$, balance $\left.\mathrm{Ar}\right)$

\begin{tabular}{|l|l|l|l|}
\hline Run \# & $\begin{array}{l}\mathrm{t}_{\mathrm{Bt}, 500} \\
(\mathrm{~min})\end{array}$ & $\begin{array}{l}\mathrm{t}_{\mathrm{Bt}, \mathrm{St}} \\
(\mathrm{min})\end{array}$ & $\begin{array}{l}\xi_{\mathrm{ZnO}}\left(\mathrm{t}_{\mathrm{Bt}, 500}\right) \\
(-)\end{array}$ \\
\hline 1 & 8.1 & 130 & 0.0620 \\
\hline 2 & 8.3 & 130 & 0.0626 \\
\hline
\end{tabular}




\section{REFERENCES}

1. United States Environmental Protection Agency, National Emission Standards for Hazardous Air Pollutants From Coal- and Oil-Fired Electric Utility Steam Generating Units and Standards of Performance for Fossil-Fuel-Fired Electric Utility, Industrial-CommercialInstitutional, and Small Industrial-Commercial-Institutional Steam Generating Units; Final Rule. In Federal Register, 2012; Vol. 77, pp 9304-9513.

2. Higman, C.; van der Burgt, M., Gasification. 2nd ed.; Elsevier: Amsterdam, 2008; p 456. 3. Stoica, P.; Moses, R. L., Spectral analysis of signals. Prentice Hall: Upper Saddle River, New Jersey, 2005; p 452.

4. Wilke, C. R., A Viscosity Equation for Gas Mixtures. The Journal of Chemical Physics 1950, 18, (4), 517-519.

5. Thibodeaux, L. J., Handbook of chemical mass transport in the environment. CRC Press: Boca Raton, 2011; p 611.

6. Fuller, E. N.; Schettler, P. D.; Giddings, J. C., New method for prediction of binary gasphase diffusion coefficients. Industrial \& Engineering Chemistry 1966, 58, (5), 18-27.

7. VDI, VDI Heat Atlas. 2nd ed.; Springer: Berlin, 2010; p 1585. 